\title{
COMMENTARY
}

\section{Erythropoietin for stroke treatment: dead or alive?}

\author{
Jens Minnerup ${ }^{* 1}$, Heike Wersching ${ }^{2}$ and Wolf-Rüdiger Schäbitz ${ }^{3}$ \\ See related research by Yip et al., http://ccforum.com/content/15/1/R40
}

\begin{abstract}
Endothelial progenitor cell (EPC) mobilization from the bone marrow was considered to improve outcome after ischemic stroke. Erythropoietin (EPO) might be a potential candidate stroke drug that increases the number of circulating EPCs. In the previous issue of Critical Care, Yip and colleagues investigated the effect of EPO in stroke patients on both clinical outcome and EPC stimulation. Although beneficial effects of EPO were observed, several issues regarding EPO's suitability as a stroke drug remain.
\end{abstract}

Endothelial progenitor cells (EPCs) are hematopoietic cells derived from immature bone marrow that circulate in the peripheral blood [1]. EPCs have the capability to differentiate into mature endothelial cells and are assumed to replace dysfunctional endothelium. Consistent with this hypothesis, decreased levels of EPCs were shown to predict atherosclerotic disease progression and to be an independent risk factor for cardiovascular events [2]. After ischemic stroke, EPC levels decrease [3]. On the other hand, increasing EPC numbers during the acute phase of stroke are associated with smaller lesion growth and with improved neurological outcome $[3,4]$. Therefore, pharmacological mobilization of EPCs from the bone marrow may enhance functional recovery poststroke. A potential candidate stroke drug that increases the number of circulating EPCs is erythropoietin (EPO) [5]. Several preclinical stroke studies demonstrated the efficacy of EPO in reducing infarct volumes and in improving recovery of neurological function [6]. However, no human stroke study so far investigated the effects of EPO on both neurological outcome and EPC levels.

In the previous issue of Critical Care, Yip and colleagues [1] report on a prospective clinical trial in which 167 ischemic stroke patients were randomized to receive either 5,000 IU EPO or placebo subcutaneously at 48 and

*Correspondence: minnerup@uni-muenster.de

'Universitätsklinikum Münster, Klinik und Poliklinik für Neurologie,

Albert-Schweitzer-Straße 33, 48149 Münster, Germany

Full list of author information is available at the end of the article
72 hours after symptom onset. On day 21, EPC levels were significantly higher in the EPO group. After 90 days, EPO treatment was associated with a significantly lower proportion of patients with a National Institute of Health Stroke Scale (NIHSS) score $\geq 8$ as well as with significant reductions in recurrent strokes and in the composite endpoint of recurrent stroke, NIHSS $\geq 8$ and death. Overall, two questions arise: is bone marrow stimulation to increase EPC levels in the peripheral blood a suitable therapy for stroke; and is EPO a candidate drug that can improve neurological outcome post-stroke by EPC stimulation?

Since increasing EPC levels post-stroke were shown to be associated with a favorable outcome, the primary question is whether EPCs are only a surrogate marker of neurological improvement or whether a causal relationship exists. Actually, both possibilities are reasonable. EPC numbers were shown to be lower in stroke patients with more severe neurological deficits who, in turn, have a reduced potential for recovery compared to patients with less severe deficits and higher EPC levels [7]. A pathophysiological explanation for the hypothesis that EPCs reflect only the severity of stroke is the assumption that larger infarcts cause an excessive consumption of EPCs for endothelial repair, with subsequent lower peripheral EPC levels [8]. However, results of experimental stroke studies suggest a causal association between EPCs and improved functional recovery because EPC administration leads to reduced infarct volumes and improved functional recovery in different animal stroke models [9-11]. Increased EPC-derived angiogenesis in the periinfarct region was identified as an underlying mechanism.

So, is EPO a suitable drug for EPC stimulation in stroke patients? Besides other mechanisms in stroke, such as anti-apoptotic effects and increasing neurogenesis and angiogenesis, EPO was found to enhance EPC numbers $[5,12]$. However, in contrast to pathophysiological considerations and results of experimental studies, the randomized phase II/III German Multicenter EPO Stroke Trial, which is the largest clinical EPO stroke study that has been published so far, was negative [13]. The primary endpoint of the German EPO Trial, change in Barthel Index on day 90, and all secondary outcomes, including the NIHSS and the modified Rankin Scale, failed to show any benefit of EPO. Moreover, in the German EPO trial increased mortality was observed after EPO treatment. 
The discrepancy with the positive findings in the study of Yip and colleagues might be explained by the chosen endpoints. The primary endpoint of the present study, which was reported at the Current Controlled Trial register [14], is the composite of recurrent stroke, NIHSS $\geq 8$ and death. This endpoint primarily reflects the frequency of recurrent stroke on day 90 . When considering the components of the composite endpoint, the significantly higher number of patients with a NIHSS $\geq 8$ after placebo treatment is also likely to be caused by the high rate of recurrent strokes and does not necessarily reflect improved neurological function in the EPO group. Concordantly, the means of the NIHSS on day 90 did not differ between the two groups. The 90-day mortality, which is the third component of the composite endpoint, was even higher in the EPO group. In contrast to the finding of increased mortality after EPO treatment in the larger German EPO trial, this difference was statistically not significant.

Overall, the results of the study of Yip and colleagues suggest that EPO might be suitable for the secondary prevention of ischemic stroke. The efficacy regarding improved neurological outcome, which is usually measured by the modified Rankin Scale or the Barthel Index at day 90, was not investigated. Moreover, the results of the study of Yip and colleagues are weakened by the fact that the study was first assigned to a trial register in January 2011, which was 10 months after the inclusion of the last patients in March 2010 [14]. Thus, the endpoints were not published before completion of the study. Furthermore, there are severe doubts regarding the potency of $\mathrm{EPO}$ as a drug for secondary stroke prevention, since long-term use of EPO was shown to even increase the risk for stroke [15].

In conclusion, the potential side effects and the failed efficacy in a large clinical trial will presumably prevent the use of EPO as a therapy to increase EPCs after stroke. However, a direct systemic transplantation of EPCs or the mobilization of EPCs by other drugs - for example, granulocyte colony-stimulating factor - remain as promising options to improve outcome after stroke [16].

\section{Abbreviations}

EPC, endothelial progenitor cell; EPO, erythropoietin; NIHSS, National Institute of Health Stroke Scale.

\section{Competing interests}

W-RS is an inventor on patent applications claiming the use of granulocyte colony-stimulating factor for the treatment of stroke, has received financial compensation as a principal investigator and has received financial compensation from SYGNIS Bioscience for consulting. The authors declare no other competing interests.

\section{Authors' contributions}

JM and HW wrote the manuscript. WRS revised the manuscript.

\section{Author details}

'Department of Neurology, University Hospital Münster, Albert-SchweitzerStraße 33, 48149 Münster, Germany. ${ }^{2}$ nnstitute of Epidemiology and Social
Medicine, University of Münster, Domagkstraße 3, 48149 Münster, Germany. ${ }^{3}$ Department of Neurology, Evangelisches Krankenhaus Bielefeld, Burgsteig 13, 33617 Bielefeld, Germany.

Published: 9 March 2011

\section{References}

1. Yip HK, Tsai TH, Lin HS, Chen SF, Sun CK, Leu S, Yuen CM, Tan TY, Lan MY, Liou $\mathrm{CW}$, Lu CH, Chang WN: Effect of erythropoietin on level of circulating endothelial progenitor cells and outcome in patients after acute ischemic stroke. Crit Care 2011, 15:R40.

2. Schmidt-Lucke C, Rossig L, Fichtlscherer S, Vasa M, Britten M, Kamper U, Dimmeler S, Zeiher AM: Reduced number of circulating endothelial progenitor cells predicts future cardiovascular events: proof of concept for the clinical importance of endogenous vascular repair. Circulation 2005, 111:2981-2987.

3. Bogoslovsky T, Chaudhry A, Latour L, Maric D, Luby M, Spatz M, Frank J, Warach $S$ : Endothelial progenitor cells correlate with lesion volume and growth in acute stroke. Neurology 2010, 75:2059-2062.

4. Sobrino T, Hurtado O, Moro MA, Rodríguez-Yáñez M, Castellanos M, Brea D, Moldes O, Blanco M, Arenillas JF, Leira R, Dávalos A, Lizasoain I, Castillo J: The increase of circulating endothelial progenitor cells after acute ischemic stroke is associated with good outcome. Stroke 2007, 38:2759-2764.

5. Bahlmann FH, De Groot K, Spandau JM, Landry AL, Hertel B, Duckert T, Boehm SM, Menne J, Haller H, Fliser D: Erythropoietin regulates endothelial progenitor cells. Blood 2004, 103:921-926.

6. Minnerup J, Heidrich J, Rogalewski A, Schabitz WR, Wellmann J: The efficacy of erythropoietin and its analogues in animal stroke models: a metaanalysis. Stroke 2009, 40:3113-3120.

7. Yip HK, Chang LT, Chang WN, Lu CH, Liou CW, Lan MY, Liu JS, Youssef AA, Chang HW: Level and value of circulating endothelial progenitor cells in patients after acute ischemic stroke. Stroke 2008, 39:69-74.

8. Zhang ZG, Zhang L, Jiang Q, Chopp M: Bone marrow-derived endothelial progenitor cells participate in cerebral neovascularization after focal cerebral ischemia in the adult mouse. Circ Res 2002, 90:284-288.

9. Fan Y, Shen F, Frenzel T, Zhu W, Ye J, Liu J, Chen Y, Su H, Young WL, Yang GY: Endothelial progenitor cell transplantation improves long-term stroke outcome in mice. Ann Neurol 2010, 67:488-497.

10. Ohta T, Kikuta K, Imamura H, Takagi Y, Nishimura M, Arakawa Y, Hashimoto N, Nozaki K: Administration of ex vivo-expanded bone marrow-derived endothelial progenitor cells attenuates focal cerebral ischemiareperfusion injury in rats. Neurosurgery 2006, 59:679-686.

11. Taguchi A, Soma T, Tanaka H, Kanda T, Nishimura H, Yoshikawa H, Tsukamoto Y, Iso H, Fujimori Y, Stern DM, Naritomi H, Matsuyama T: Administration of CD34+ cells after stroke enhances neurogenesis via angiogenesis in a mouse model. J Clin Invest 2004, 114:330-338.

12. Minnerup J, Schabitz WR: Multifunctional actions of approved and candidate stroke drugs. Neurotherapeutics 2009, 6:43-52.

13. Ehrenreich $H$, Weissenborn $K$, Prange $H$, Schneider D, Weimar C, Wartenberg K, Schellinger PD, Bohn M, Becker H, Wegrzyn M, Jähnig P, Herrmann M, Knauth M, Bähr M, Heide W, Wagner A, Schwab S, Reichmann H, Schwendemann G, Dengler R, Kastrup A, Bartels C; EPO Stroke Trial Group: Recombinant human erythropoietin in the treatment of acute ischemic stroke. Stroke 2009, 40:e647-e656.

14. ISRCTN: Effect of erythropoietin on level of circulating endothelial progenitor cells and outcome in patients after acute ischaemic stroke [http://www.controlled-trials.com/ISRCTN71371114/]

15. Pfeffer MA, Burdmann EA, Chen CY, Cooper ME, de Zeeuw D, Eckardt KU, Feyzi JM, Ivanovich P, Kewalramani R, Levey AS, Lewis EF, McGill JB, McMurray J, Parfrey P, Parving HH, Remuzzi G, Singh AK, Solomon SD, Toto R; TREAT Investigators: A trial of darbepoetin alfa in type 2 diabetes and chronic kidney disease. N Engl J Med 2009, 361:2019-2032.

16. Powell TM, Paul JD, Hill JM, Thompson M, Benjamin M, Rodrigo M, McCoy JP, Read EJ, Khuu HM, Leitman SF, Finkel T, Cannon RO 3rd: Granulocyte colonystimulating factor mobilizes functional endothelial progenitor cells in patients with coronary artery disease. Arterioscler Thromb Vasc Biol 2005, 25:296-301.

doi:10.1186/cc10057

Cite this article as: Minnerup J, et al.: Erythropoietin for stroke treatment: dead or alive? Critical Care 2011, 15:129. 